\title{
A New Electrochemical Platform Based on a Polyurethane Composite Electrode Modified with Magnetic Nanoparticles Coated with Molecularly Imprinted Polymer for the Determination of Estradiol Valerate in Different Matrices
}

\author{
Bruna Bergamin,,$^{\#, a, b}$ Rafael R. Pupin, ${ }^{\#, a, b}$ Ademar Wong ${ }^{\sharp, a, b}$ and Maria D. P. T. Sotomayor ${ }^{\circledR *, a, b}$ \\ ${ }^{a}$ Departamento de Química Analítica, Instituto de Química, \\ Universidade Estadual Paulista (Unesp), 14801-970 Araraquara-SP, Brazil \\ ${ }^{b}$ Instituto Nacional de Tecnologias Alternativas para Detecção, Avaliação Toxicológica e \\ Remoção de Micropoluentes e Radioativos (INCT-DATREM), 14801-970 Araraquara-SP, Brazil
}

\begin{abstract}
A polyurethane composite electrode modified with magnetic nanoparticles (mag; $\mathrm{Fe}_{3} \mathrm{O}_{4}$ ) coated with molecularly imprinted polymers (MIPs) was developed for the electrochemical determination of estradiol valerate. Chemical and morphological analyses of the mag-MIP were performed using scanning electron microscopy (SEM) and energy dispersive X-ray spectroscopy (EDS), with the aim of characterizing this new material. The efficiency of adsorption of estradiol valerate by the mag-MIP was tested in binding experiments using an electrochemical method. For this, different electrodes (mag-MIP / graphite-epoxy composite (GEC), mag-non-imprinted polymer (NIP) / GEC, mag / GEC, and GEC) were evaluated by square-wave voltammetry (SWV). After $10 \mathrm{~min}$ at open circuit potential, increases in the current signal of 1.9, 2.1, and 3.0 times were obtained, comparing the electrochemical response of the mag-MIP / GEC sensor to the mag-NIP / GEC, mag / GEC, and GEC sensors, respectively. Under optimized conditions, the mag-MIP / GEC showed a linear concentration range for estradiol valerate of $5.0 \times 10^{-7}$ to $7.5 \times 10^{-4} \mathrm{~mol} \mathrm{~L}^{-1}$ and a limit of detection of $1.0 \times 10^{-8} \mathrm{~mol} \mathrm{~L}^{-1}$. The proposed sensor was applied in the analysis of pharmaceutical, human urine, and river water samples. The recovery values determined using high performance liquid chromatography (HPLC)-UV and the electrochemical method were in agreement and were near $100 \%$, demonstrating the reliability of the proposed method.
\end{abstract}

Keywords: polyurethane composite electrode, estradiol valerate, environmental samples, pharmaceuticals, MIP, selective adsorption

\section{Introduction}

Estrogenic substances such as the estradiol valerate hormone are important endocrine disruptors that interfere with the natural functioning of the endocrine system, and are also often released to the environment without any adequate control. ${ }^{1,2} \mathrm{~A}$ major concern related to these hormones centers on the adverse effects that they have in the reproductive systems of living beings, such as the feminization of fish, since the compounds can be easily adsorbed in the sediments of aquatic systems., ${ }^{3,4}$ Although they have relatively short half-lives (around 10 days), compared to certain other organic compounds (such as some pesticides), the estrogens are of great concern because they are continuously discharged into the environment. ${ }^{5}$

*e-mail: mpilarts@ hotmail.com, m.sotomayor@unesp.br

"These authors contributed equally to this work
The development of selective and sensitive analytical methods is of great importance for the determination of these compounds. ${ }^{6}$ Due to the complexity of some matrices, the low levels of the compounds, and the presence of interferents, it can be difficult to perform separation and concentration procedures. In this regard, the use of molecularly imprinted polymers (MIPs) has been shown to be an efficient analytical approach. ${ }^{7-9}$

Magnetic nanoparticles (mag) are among the materials most commonly employed as a core for MIPs, with iron oxides being favored due to their excellent properties including superparamagnetism and high stability. Maghemite $\left(\gamma-\mathrm{Fe}_{2} \mathrm{O}_{3}\right)$ and magnetite $\left(\mathrm{Fe}_{3} \mathrm{O}_{4}\right)$ are the most widely used oxides, because they possess the abovementioned properties and also have proven low toxicity and good biocompatibility. ${ }^{10,11}$ Among the various advantages presented by these nanoparticles, the most important are their surface characteristics, which allow their easy encapsulation and surface modification 
to protect them from degradation, while retaining their good magnetic response. ${ }^{12,13}$ The modifications range from simple functionalization on the surface, involving different functional groups, to the use of organic molecules (surfactants, polymers, and biological components). ${ }^{14,15}$ In this way, combining the properties of the magnetic material with those of the MIPs can be used to produce $\mathrm{Fe}_{3} \mathrm{O}_{4}$-MIPs consisting of magnetic nanoparticles decorated / modified with molecularly imprinted polymers, in order to obtain new sensor platforms for use in magnetic electrodes. Furthermore, mag-MIPs can mimic biological receptors, so they can be considered as biomimetic polymeric substances that can perform the same function as biological receptors, but that have much greater durability. ${ }^{16,17}$ The modification of $\mathrm{Fe}_{3} \mathrm{O}_{4}$-MIP in electrochemical devices has attracted great attention due to the innumerable advantages that can be obtained as high sensitivity, selectivity, stability, repeatability, and low cost. ${ }^{18,19}$ The identification and separation of the analyte selectively adsorbed in the MIP using magnetic properties $\left(\mathrm{Fe}_{3} \mathrm{O}_{4}\right.$-MIP) makes this device highly promising, allowing analysis with success in different matrices. The results obtained with this methodology are similar and many times better than the other analytical methods. To date, few electrochemical sensors using this methodology are described in which the MIPs is captured by magnetic electrode..$^{9,20,21}$

The purpose of this work was to obtain new sensors with the desired characteristics of high selectivity and robustness, aiming at real applications. As a contribution to addressing environmental and public health concerns, an electrochemical sensor was developed based on a polyurethane composite electrode with magnet modified with mag-MIP. The electrochemical determination of estradiol valerate was performed in pharmaceutical samples of synthetic urine and river water.

\section{Experimental}

\section{Reagents and solutions}

All reagents used were of analytical or high performance liquid chromatography (HPLC) grade. All solutions were prepared with deionized water (resistivity $\geq 18 \mathrm{M} \Omega \mathrm{cm}$ at $25^{\circ} \mathrm{C}$ ) obtained from a Millipore Milli- $\mathrm{Q}^{\circledR}$ system. The reagents used in this work were as follows: estradiol valerate, methacrylic acid, acrylonitrile, 2-vinylpyridine, 1-vinylimidazole, trimethylolpropane trimethacrylate (TRIM), ethylene glycol dimethacrylate (EGDMA), $\mathrm{FeCl}_{2} \cdot 4 \mathrm{H}_{2} \mathrm{O}, \mathrm{FeCl}_{3} \cdot 6 \mathrm{H}_{2} \mathrm{O}$, tetraethyl orthosilicate (TEOS), methacryloxypropyl trimethoxysilane (MPS), and 2,2-azobisobutyronitrile (AIBN), acquired from Sigma-Aldrich
(St. Louis, USA); $\mathrm{KH}_{2} \mathrm{PO}_{4}, \mathrm{~K}_{2} \mathrm{HPO}_{4}, \mathrm{HCl}, \mathrm{NaOH}$, glacial acetic acid, $\mathrm{NH}_{4} \mathrm{OH}$, ethanol, and toluene, obtained from Neon (Suzano, Brazil); and methanol, acquired from J.T. Baker (Mexico City, Mexico).

\section{Chemical and morphological characterization}

Morphological characterization of the nanomaterials was performed by scanning electron microscopy (SEM) using a Hitachi S-4800 microscope, and chemical analysis (energy-dispersive X-ray spectroscopy (EDS)) was performed using a Zeiss LEO 440 microscope (model 7060) operated with a $20 \mathrm{kV}$ electron beam. For that, a mass of the nanomaterials was weighed and suspended in deionized water using an ultrasonic bath for $15 \mathrm{~min}$. An aliquot of $15 \mu \mathrm{L}$ of each suspension was dropped onto a glassy carbon plate $\left(1.0 \times 1.0 \mathrm{~cm}^{2}\right)$, and the solvent was evaporated at room temperature.

\section{Electrochemical measurements}

The electrochemical measurements were carried out using an Autolab PGSTAT 302N potentiostat controlled by NOVA 2.2 software and equipped with a conventional electrochemical cell (10 mL volume) containing three electrodes. The electrodes used were an $\mathrm{Ag} / \mathrm{AgCl} / \mathrm{KCl}_{\text {sat }}$ reference electrode, a platinum coil counter electrode, and graphite-epoxy composite (GEC) as the homemade working electrode $(\mathrm{WE})(\mathrm{r}=1.3 \mathrm{~mm})$.

\section{HPLC-UV analysis}

The equipment used was a Shimadzu 20A chromatograph fitted with a UV / visible detector (model SPD-20A), an auto-injector (model SIL-20A), and a degasser (model DGU-20A5). The stationary phase utilized for HPLC analysis was a reversed phase C18 column (Shim-pack CLC, Shimadzu). The mobile phase was a mixture of $0.1 \mathrm{~mol} \mathrm{~L}^{-1}$ acetonitrile and ammonium nitrate $(70: 30 \mathrm{v} / \mathrm{v})$,

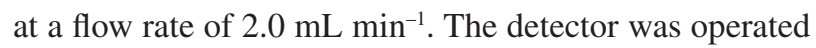
at a wavelength of $280 \mathrm{~nm} .^{20}$

\section{Preparation of the electrochemical sensor}

The procedure employed to prepare the polyurethane composite electrode was as described by Pividori and Alegret, ${ }^{21}$ using a mixture of graphite powder (Saint Louis, USA) and Epotek $\mathrm{H} 77$ resin and hardener (both from Epoxy Technology, Billerica, USA) in a 1:4 (m/m) ratio (graphite powder:epoxy resin). The paste obtained was filled to a depth of $3 \mathrm{~mm}$, covering a neodymium magnet, 
in a cylindrical polyvinyl chloride (PVC) sleeve body (6 $\mathrm{mm}$ i.d.) with an electrical contact, and was cured at $40{ }^{\circ} \mathrm{C}$ for one week. After this step, the electrode was washed with deionized water and polished with 600-grit sandpaper.

\section{Synthesis of the mag-MIP}

Synthesis of the mag-MIP was performed with magnetic nanoparticles $\left(\mathrm{Fe}_{3} \mathrm{O}_{4}\right)$ prepared by the co-precipitation method, using $1.6 \times 10^{-2} \mathrm{~mol} \mathrm{FeCl}_{3} \cdot 6 \mathrm{H}_{2} \mathrm{O}$ and $7.8 \times 10^{-3} \mathrm{~mol} \mathrm{FeCl}_{2} \cdot 4 \mathrm{H}_{2} \mathrm{O}$ in $40 \mathrm{~mL}$ of deionized water, under an inert nitrogen atmosphere and with constant agitation. ${ }^{22,23}$ Addition was made of a $1.5 \mathrm{~mol} \mathrm{~L}^{-1} \mathrm{NaOH}$ solution (approximately $50 \mathrm{~mL}$ ), under constant agitation, until reaching $\mathrm{pH} 10$, with the appearance of a black precipitate indicating the formation of magnetite. $\mathrm{The} \mathrm{Fe}_{3} \mathrm{O}_{4}$ was washed, separated with a magnet, and dried at room temperature. Next, the $\mathrm{Fe}_{3} \mathrm{O}_{4}$ was modified with TEOS $\left(\mathrm{Fe}_{3} \mathrm{O}_{4} @ \mathrm{SiO}_{2}\right)$ to provide $\mathrm{OH}$ groups for further reaction. Around $300 \mathrm{mg}$ of $\mathrm{Fe}_{3} \mathrm{O}_{4}$ were mixed with $4 \mathrm{~mL}$ of water, $40 \mathrm{~mL}$ of ethanol, and $5 \mathrm{~mL}$ of aqueous ammonia. The dispersion was homogenized by ultrasonication, followed by the slow addition of TEOS to the dispersion, with stirring for $12 \mathrm{~h}$. After this step, silanization of the material obtained was performed using $250 \mathrm{mg}$ of $\mathrm{Fe}_{3} \mathrm{O}_{4} @ \mathrm{SiO}_{2}, 45 \mathrm{~mL}$ of toluene, and $5 \mathrm{~mL}$ of MPS, under a nitrogen atmosphere for $12 \mathrm{~h}$, in order to provide activated $\mathrm{C}=\mathrm{C}$ groups. The material formed was washed using ethanol and deionized water, followed by drying at room temperature, resulting in $\mathrm{Fe}_{3} \mathrm{O}_{4} @ \mathrm{SiO}_{2}$-MPS.

Finally, the mag-MIP was modified using masses of $0.2 \times 10^{-3} \mathrm{~mol}$ estradiol valerate and $0.8 \times 10^{-2} \mathrm{~mol}$ methacrylic acid (functional monomer), in $25 \mathrm{~mL}$ of methanol, under an anaerobic atmosphere $\left(\mathrm{N}_{2}\right)$, at a temperature of $25^{\circ} \mathrm{C}$. The reaction was allowed to complete during $24 \mathrm{~h}$. In the next step, $200 \mathrm{mg}$ of the modified $\mathrm{Fe}_{3} \mathrm{O}_{4} @ \mathrm{SiO}_{2}$-MPS was stirred for $2 \mathrm{~h}$, followed by addition of $3.0 \times 10^{-3} \mathrm{~mol} \mathrm{TRIM} \mathrm{(crosslinking} \mathrm{reagent)} \mathrm{and}$ $5.0 \times 10^{-2} \mathrm{~mol}$ AIBN (radical initiator). In order to initiate the photopolymerization, the mixture was irradiated for $2 \mathrm{~h}$ using a quartz high pressure $\mathrm{Hg}$ vapor lamp (125 W), since the estradiol valerate molecule is unstable at $60{ }^{\circ} \mathrm{C}$, making thermal polymerization impossible. After the polymerization process, the final material was washed several times for complete removal of the analyte and other reagents (Scheme 1). A control polymer (mag-nonimprinted polymer (NIP)) was prepared following the same procedure, but without introduction of the template molecule.

\section{Electrochemical experiments}

Tests of adsorption of estradiol valerate were performed by an electrochemical method using the mag-MIP / GEC and mag-NIP / GEC, with the addition of $4.0 \mathrm{mg}$ of polymer in $10.0 \mathrm{~mL}$ of aqueous solution of estradiol valerate at different concentrations, in $20 \mathrm{~mL}$ flasks. For each concentration, the mag-polymer and the analyte were mixed slowly for $10 \mathrm{~min}$ using a homogenizer, followed by separation of the materials using a magnetic bar (the working electrode) and then washing with deionized water in order to remove the unbound chemical compounds. The optimization of polymer mass $(2,4$, and $6 \mathrm{mg})$ and adsorption time $(0,2,5,10,15$, and $30 \mathrm{~min})$ were based on the highest intensity of the analytical signal obtained in the square-wave voltammetry (SWV) experiments (not shown).

(a)

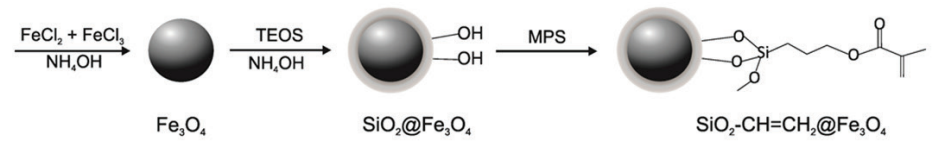

(b)
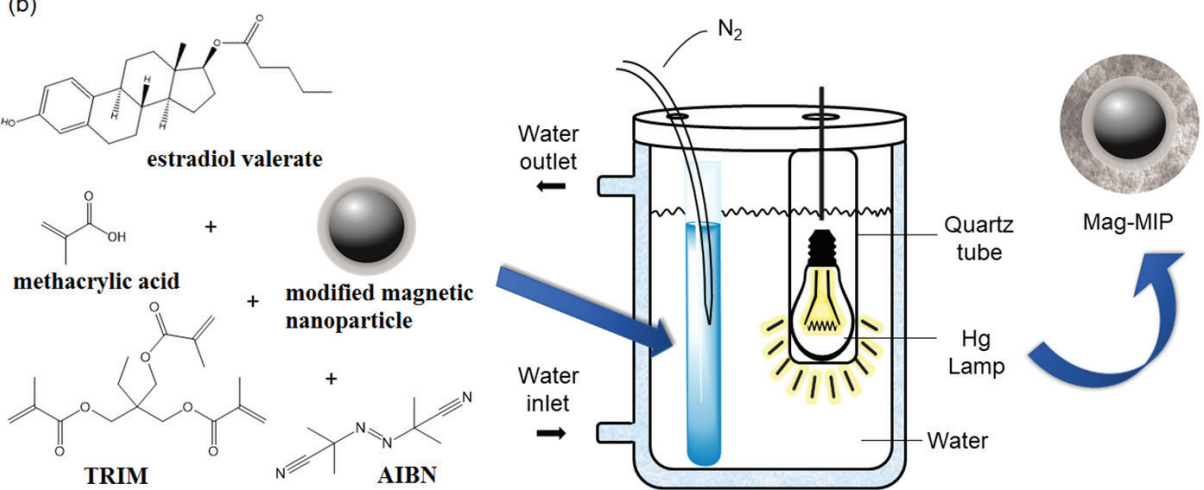

Scheme 1. Schematic representation of the synthesis of (a) magnetic nanoparticles and chemical modification with TEOS and MPS, and (b) mag-MIP. 
The concentration of adsorbed estradiol valerate by mag-MIP was determined using an electrochemical cell containing $10.0 \mathrm{~mL}$ of electrolyte $(50: 50(\mathrm{v} / \mathrm{v})$ methanol and $0.1 \mathrm{~mol} \mathrm{~L}^{-1}$ phosphate buffer, at $\mathrm{pH} 7.0$ ). Scheme 2 shows the steps of the estradiol valerate adsorption by mag-MIP: (a) incubation step with the mag-MIP in the analyte solution; (b) selective adsorption by the mag-MIP; (c) removal of the analyte-mag-MIP with the electrode magnet; (d) and (e) analysis of the modified analyte-mag-MIP electrode in an electrochemical cell using the SWV method. Before the electrochemical measurements, the mag-MIP is removed, and the electrode surface is regenerated by simple polishing with 600 -grit sandpaper.

Application of the sensor using pharmaceutical, and river water samples

The pharmaceutical formulation samples were prepared using ten tablets that were ground and homogenized in a mortar. A suitable amount of triturated sample was then weighed out and dissolved in deionized water, followed by a simple filtration step in order to remove any insoluble substances present in the sample. One concentration was prepared for analysis by the electrochemical and HPLC methods. The synthetic urine sample was prepared in a $50.0 \mathrm{~mL}$ volumetric flask using the following reagents and concentrations: $4.0 \times 10^{-2} \mathrm{~mol} \mathrm{~L}^{-1} \mathrm{KCl}, 1.0 \times 10^{-1} \mathrm{~mol} \mathrm{~L}^{-1}$ $\mathrm{NaCl}, 3.0 \times 10^{-2} \mathrm{~mol} \mathrm{~L}^{-1} \mathrm{KH}_{2} \mathrm{PO}_{4}, 2.0 \times 10^{-2} \mathrm{~mol} \mathrm{~L}^{-1}$ $\mathrm{CaCl}_{2}, 3.6 \times 10^{-2} \mathrm{~mol} \mathrm{~L}^{-1} \mathrm{NH}_{4} \mathrm{Cl}$ and $3.6 \times 10^{-2} \mathrm{~mol} \mathrm{~L}^{-1}$ urea. ${ }^{24}$ The flask volume was completed with ultrapure water. River water samples were collected from different rivers in the municipality of Araraquara (São Paulo State, Brazil), at different depths, and were then mixed. The total volume of the samples was subjected to conventional filtration for removal of solid material, followed by storage in a $5 \mathrm{~L}$ flask, in a refrigerator. The prepared samples were spiked with estradiol valerate at two concentration levels $\left(1.0 \times 10^{-6}\right.$ and $\left.5.0 \times 10^{-6} \mathrm{~mol} \mathrm{~L}^{-1}\right)$ and were analyzed by the electrochemical and HPLC methods.

\section{Results and Discussion}

\section{Morphological and chemical characterization}

The morphological characteristics of the mag-MIP were evaluated using images acquired with a SEM (model 7500F, JEOL). Figure 1a shows the $\mathrm{Fe}_{3} \mathrm{O}_{4}$ nanoparticles, which presented a distribution of agglomerated spheres with a mean size of 15-30 nm. These magnetic nanoparticles were modified with TEOS and were silanized with MPS $\left(\mathrm{Fe}_{3} \mathrm{O}_{4} @\right.$ TEOS-MPS) (Figure 1b). The modification with TEOS and MPS promoted a greater increase of the particle size (120-180 nm), due to the coating on the $\mathrm{Fe}_{3} \mathrm{O}_{4}$ nanoparticles. The photopolymerization process on the mag $\left(\mathrm{Fe}_{3} \mathrm{O}_{4} @\right.$ TEOS-MPS), forming a polymeric material (MIP and NIP) with a rough aspect with particle size $(190-260 \mathrm{~nm})$ can be found in Figures 1c and 1d, respectively. Chemical analysis of the materials revealed the presence of iron and oxygen proving the presence of $\mathrm{Fe}_{3} \mathrm{O}_{4}$ nanoparticles (Figure 1e). Also, in Figure 1f was verified the presence of carbon, oxygen and silicon, and (a)

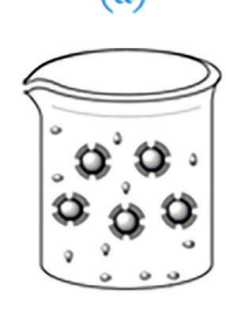

(b)

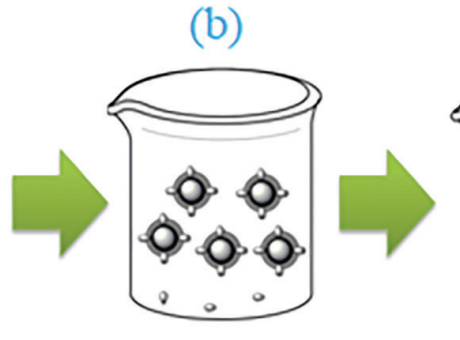

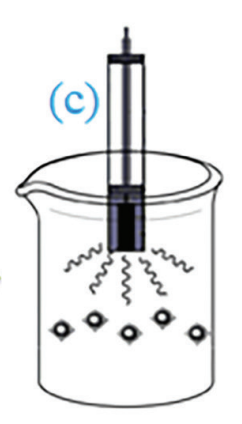

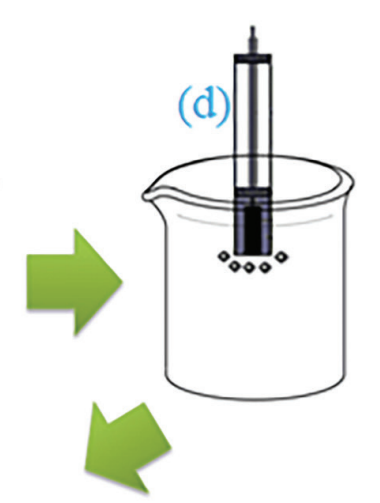

(e)

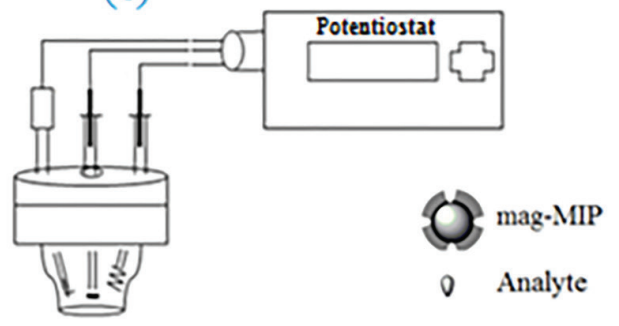

Scheme 2. Illustration of the electrochemical procedure of estradiol valerate detection using the mag-MIP sensor. 
absence of iron demonstrating that the $\mathrm{Fe}_{3} \mathrm{O}_{4}$ nanoparticles were coated with MIP (Figure 1f).

In addition, $\mathrm{Fe}_{3} \mathrm{O}_{4}$ and mag-MIP syntheses have been studied by our group in different researches. Uzuriaga-Sánchez et al. ${ }^{25}$ studied the crystalline structure of the materials $\left(\mathrm{Fe}_{3} \mathrm{O}_{4}, \mathrm{Fe}_{3} \mathrm{O}_{4} @ \mathrm{SiO}_{2}\right.$ and mag-MIP) by $\mathrm{X}$-ray diffraction (XRD). The analysis showed well-defined diffraction peaks $(2 \theta=27.20,35.58,43.14,53.48,57.08$ and $62.66^{\circ}$ ) to which the values of interplanar distances were assigned. After comparing the experimental data with database and literature, the results confirmed the crystalline cubic spinel structure of magnetite. ${ }^{26}$

\section{Electrochemical profiling of the electrodes by the SWV method}

Firstly, 3 cycles were performed by cyclic voltammetry in the potential range from 0 to $1.1 \mathrm{~V}$, at a scan rate of $50 \mathrm{mV} \mathrm{s}^{-1}$, using a 50:50 (vol\%) mixture of methanol and
$0.10 \mathrm{~mol} \mathrm{~L}^{-1}$ phosphate buffer solution ( $\mathrm{pH} 7.0$ ), in order to stabilize the background current of the electrodes. Elucidation of the behavior of the mag-MIP was performed using comparative tests with the GEC, mag / GEC, mag-MIP / GEC, and mag-NIP / GEC electrodes. Figure 2a shows the electrochemical profiles of estradiol valerate $\left(4.5 \times 10^{-5} \mathrm{~mol} \mathrm{~L}^{-1}\right)$ obtained by SWV. A well-defined analyte anodic peak current was observed at a potential of $0.5 \mathrm{~V}$. The anodic peak current values (in $\mu \mathrm{A}$ ) were 0.6 (GEC), 0.86 (mag / GEC), 0.93 (mag-NIP / GEC), and 1.80 (mag-MIP / GEC). The results clearly showed an increase of the peak current that was associated with the high adsorption of MIP and the large surface area of the $\mathrm{Fe}_{3} \mathrm{O}_{4} @ \mathrm{SiO}_{2}-\mathrm{MPS}$. The TEOS reagent generates a porous silica surface around the magnetite nanoparticles, which contributed to increase of the roughness and consequently increasing the surface area. The value for the mag-MIP / GEC sensor was 3.0-, 2.1-, and 1.9-fold higher, compared to the GEC, mag / GEC, and mag-NIP / GEC sensors,
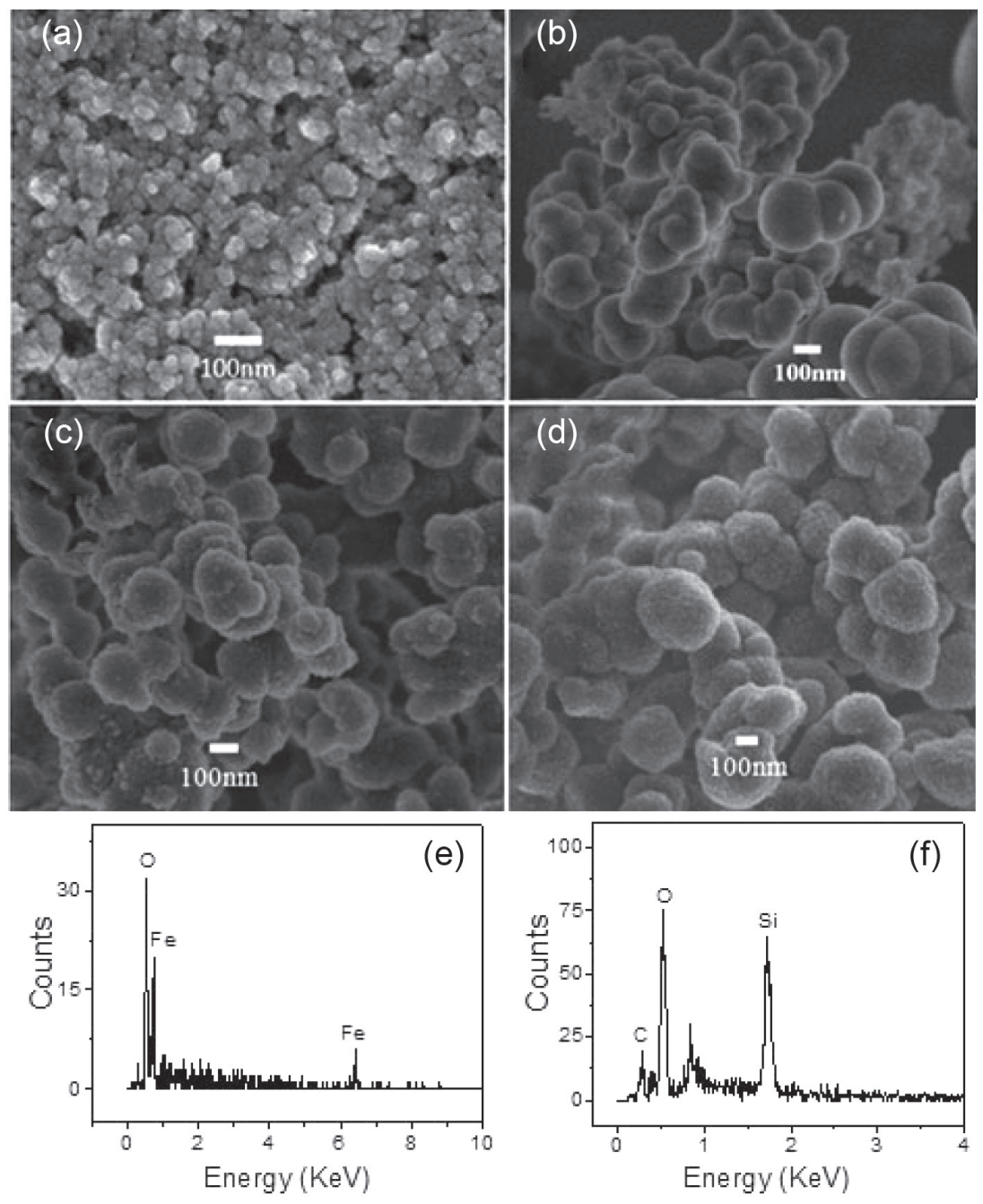

Figure 1. SEM images of the synthesis steps of mag-MIP: (a) $\mathrm{Fe}_{3} \mathrm{O}_{4}$ nanoparticles; (b) magnetic nanoparticles modified with TEOS and MPS $\left(\mathrm{Fe}_{3} \mathrm{O}_{4} @\right.$ TEOS-MPS); (c) mag-MIP; (d) mag-NIP; (e) and (f) chemical analysis by EDS of $\mathrm{Fe}_{3} \mathrm{O}_{4}$ and mag-NIP, respectively. 
respectively $(\mathrm{n}=3$ ) (Figure $2 \mathrm{~b})$. The modified magnetic nanoparticles $\left(\mathrm{Fe}_{3} \mathrm{O}_{4} @ \mathrm{SiO}_{2}\right.$-MPS $)$ provided a small increase of the current signal for the mag / GEC and mag-NIP / GEC sensors, while the combination with MIP (mag-MIP) led to a significant increase in the current signal. This increase could be attributed to the selective adsorption of the analyte by MIP. It should be emphasized that the same behavior was not observed for the NIP (control polymer). In Figure S5 (Supplementary Information (SI) section) is proposed a plausible mechanism based on previously described work.

\section{Influence of the type of electrolyte and $\mathrm{pH}$}

Firstly, tests were performed using Britton-Robinson and phosphate buffer electrolytes at $\mathrm{pH}$ 7.0, with the best response being obtained for the phosphate buffer. The

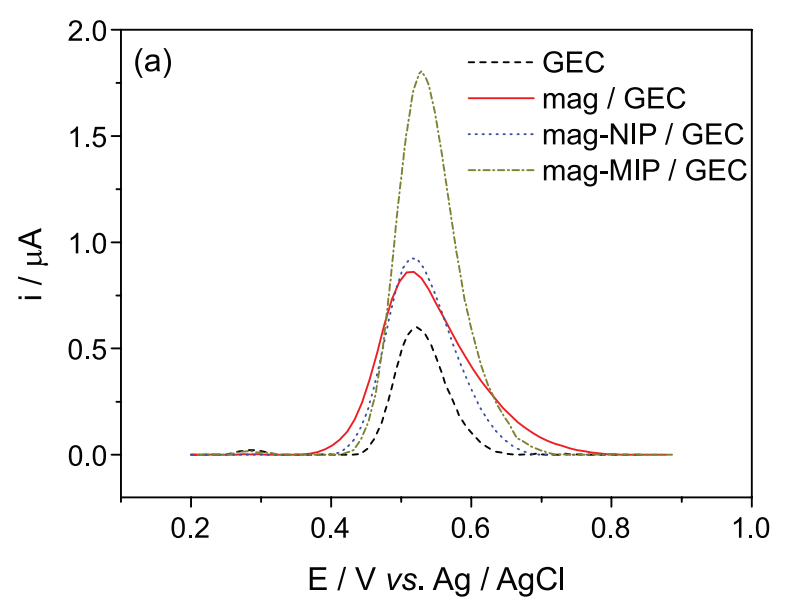

composition of the electrolyte was then studied, in order to obtain the best electrochemical signal with the proposed method, using $0.1 \mathrm{~mol} \mathrm{~L}^{-1}$ phosphate buffer solution with different proportions of methanol. Methanol was chosen as the solvent because it was used in the MIP synthesis and in the estradiol valerate adsorption assays. It can be clearly seen from Figure 3a that the best electrolyte was 50:50 (v/v) phosphate buffer:methanol.

The influence of $\mathrm{pH}$ (hydrogen ion concentration) on the response of the mag-MIP / GEC sensor was evaluated by SWV, using 50:50 (v/v) methanol and $0.1 \mathrm{~mol} \mathrm{~L}^{-1}$ phosphate buffer solutions with $\mathrm{pH}$ ranging between 5.0 and 9.0. The signal showed a maximum at $\mathrm{pH} 7$ (Figure 3b). Based on the $\mathrm{p} K_{\mathrm{a}}$ value at $298.15 \mathrm{~K}$ for estradiol valerate $\left(\mathrm{p} K_{\mathrm{a}}=10.3\right)$, the estradiol valerate molecule is present in the fully protonated form at $\mathrm{pH}$ 7.0. The inset in Figure 3b shows plots of the current (i) $v s$. potential (E) and the peak

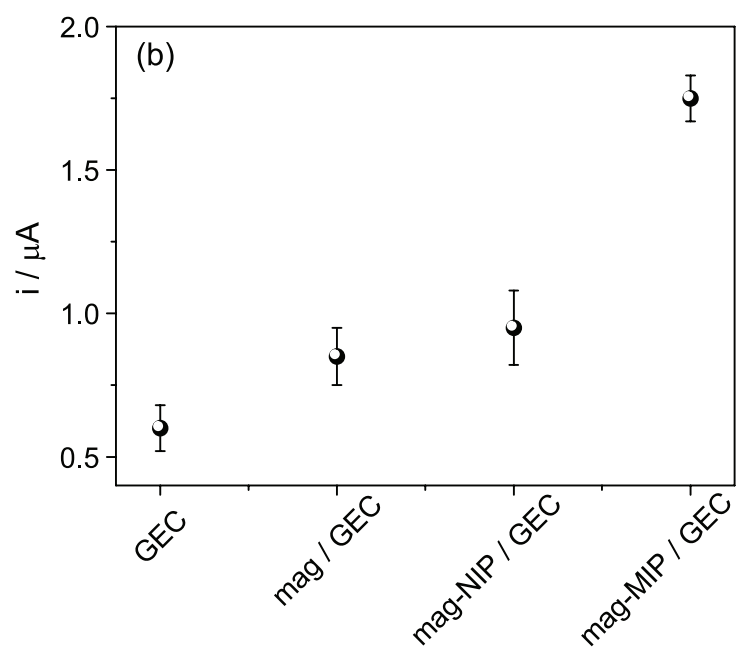

Figure 2. SWV obtained for the modified electrodes (GEC, mag / GEC, mag-NIP / GEC, and mag-MIP / GEC) in the presence of (a) $4.5 \times 10^{-5} \mathrm{~mol} \mathrm{~L} \mathrm{~L}^{-1}$ of estradiol valerate, and (b) peak current obtained in triplicate experiments. Analysis conditions: $0.1 \mathrm{~mol} \mathrm{~L}^{-1}$ phosphate buffer solution ( $\left.\mathrm{pH} 7.0\right)$ and methanol $(50: 50, \mathrm{v} / \mathrm{v})$. SWV conditions: frequency $(\mathrm{f})=10 \mathrm{~Hz}$, amplitude $(\mathrm{a})=75 \mathrm{mV}$, increment of potential $\left(\Delta \mathrm{E}_{\mathrm{s}}\right)=5 \mathrm{mV}$.
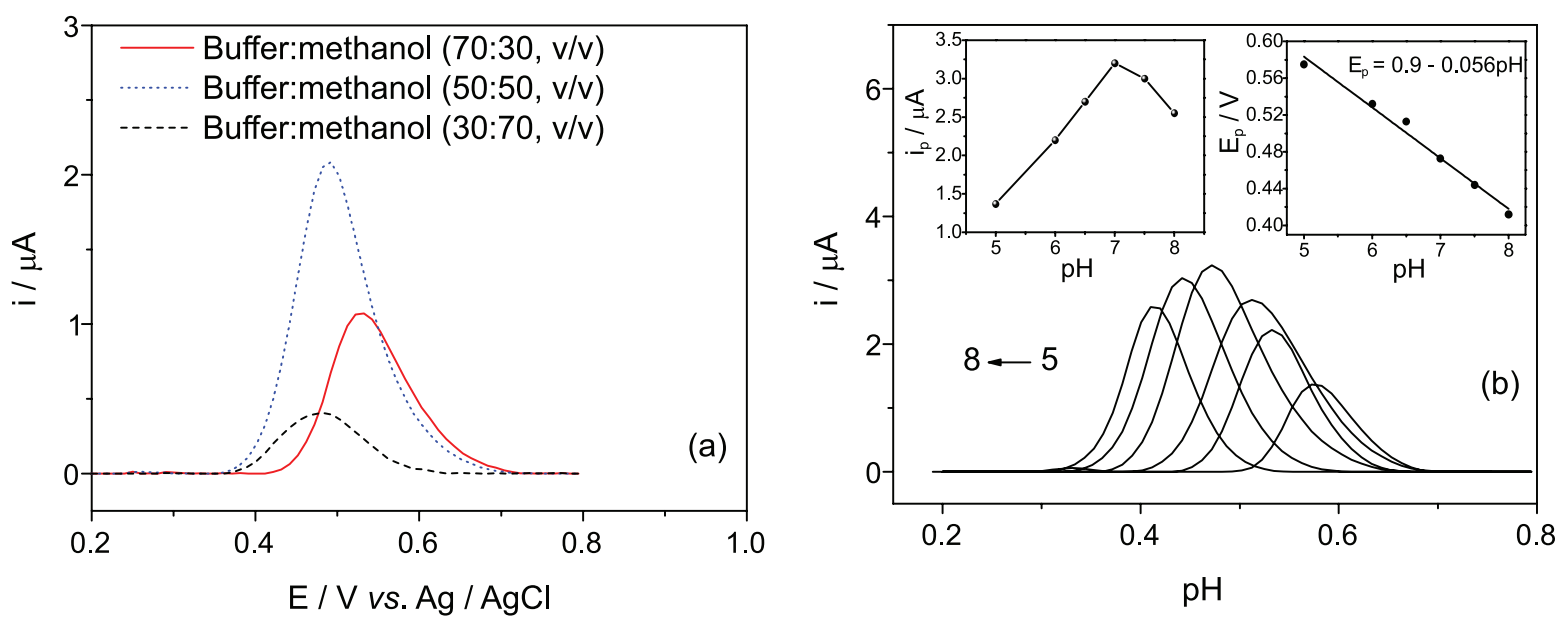

Figure 3. Study of the effects on the electrochemical response, in the presence of $7.5 \times 10^{-5} \mathrm{~mol} \mathrm{~L}^{-1}$ of estradiol valerate, of the (a) electrolyte ratio (phosphate buffer and methanol) and (b) $\mathrm{pH}$, using $0.1 \mathrm{~mol} \mathrm{~L}^{-1}$ phosphate buffer solution and methanol (50:50, v/v). SWV conditions: $\mathrm{f}=10 \mathrm{~Hz}, \mathrm{a}=75 \mathrm{mV}, \Delta \mathrm{E}_{\mathrm{s}}=5 \mathrm{mV}$. 
potential $\left(\mathrm{E}_{\mathrm{p}}\right)$ vs. $\mathrm{pH}$. A linear relationship between $\mathrm{E}_{\mathrm{p}}$ and $\mathrm{pH}$ was observed for estradiol valerate. The regression equation and correlation coefficient (r) obtained were:

$\mathrm{E}_{\mathrm{p}}=0.9-0.056 \mathrm{pH}(\mathrm{r}=0.996)$

In equation 1, the slope corresponded to the electrooxidation of estradiol valerate, with a value of $-0.056 \mathrm{~V} \mathrm{pH}^{-1}$. This slope was close to the theoretical Nernstian slope of $-0.059 \mathrm{~V} \mathrm{pH}^{-1}$ typical of redox reactions involving the same number of electrons and protons. Hence, the electrochemical reaction of estradiol valerate involved the same number of electrons and protons, in agreement with the electrooxidation mechanism reported previously. ${ }^{27,28}$

\section{Study of scan rate}

The effect of scan rate on the electrochemical response was studied by cyclic voltammetry using concentrations of $1.0 \times 10^{-4} \mathrm{~mol} \mathrm{~L}^{-1}$ estradiol valerate in $0.1 \mathrm{~mol} \mathrm{~L}^{-1}$ phosphate buffer solution and methanol $(50: 50, \mathrm{v} / \mathrm{v})$ in order to evaluate whether the redox process at the modified electrode was controlled by diffusion and / or adsorption. Cyclic voltammograms were recorded with potential scan rates ranging from 10 to $200 \mathrm{mV} \mathrm{s}^{-1}$. An increase of the peak current was observed with increasing scan rate, as expected (Figure 4). The insets in Figure 4 show plots of the current $v s$. the square root of the scan rate $\left(\mathrm{i}_{\mathrm{pa}} v s . \mathrm{v}^{1 / 2}\right)$ and the current $v s$. the scan rate $\left(\mathrm{i}_{\mathrm{pa}} v s\right.$. v). It can be clearly seen that the best linear plot was obtained for $\mathrm{i}_{\mathrm{pa}} v s . \mathrm{v}$, with a correlation coefficient of 0.9970 , compared to a value of 0.9475 for $\mathrm{i}_{\mathrm{pa}} v s . \mathrm{v}^{1 / 2}$, indicating that the estradiol valerate electrochemical response was controlled by an adsorption process, as expected.

\section{Electrochemical determination of estradiol valerate by SWV}

The SWV technique was used for the electrochemical determination of estradiol valerate. Initial experiments were performed to optimize the analytical parameters. The optimum values for amplitude (a), frequency (f), and increment of potential $\left(\Delta \mathrm{E}_{\mathrm{s}}\right)$ were based on the highest analytical signal intensity (peak current). Under optimized conditions, the mag-MIP / GEC sensor showed an increase of the analytical signal as the concentration of estradiol valerate in the electrochemical cell increased. The dependency between the analytical signal and the concentration of the analyte resulted in an analytical curve with a linear concentration range of $5.0 \times 10^{-7}$ to $7.5 \times 10^{-4} \mathrm{~mol} \mathrm{~L}^{-1}$ and a limit of detection (LOD) of $5.0 \times 10^{-8} \mathrm{~mol} \mathrm{~L}^{-1}$ (Figure 5). The LOD was calculated using $\mathrm{LOD}=3 \times \mathrm{SD} / \mathrm{m}$, where $\mathrm{SD}$ is the standard deviation for ten blank solution measurements $(n=10)$ and $m$ is the analytical sensitivity. The literature reports several studies involving the electrochemical determination of estradiol valerate, but there have been no investigations using this platform. The sensor provided excellent analytical performance, showing good sensitivity, repeatability, reproducibility, and stability in determination of estradiol valerate, with LOD and / or linear concentration ranges similar to those obtained in previous studies (Table 1).

\section{Repeatability and interference studies}

The intra- and inter-day repeatability of the mag-MIP / GEC sensor were evaluated by performing 10 measurements using SWV and $5.0 \times 10^{-5} \mathrm{~mol} \mathrm{~L}^{-1}$ estradiol valerate (Figure S2, SI section). The relative standard deviation (RSD) of the peak current was less

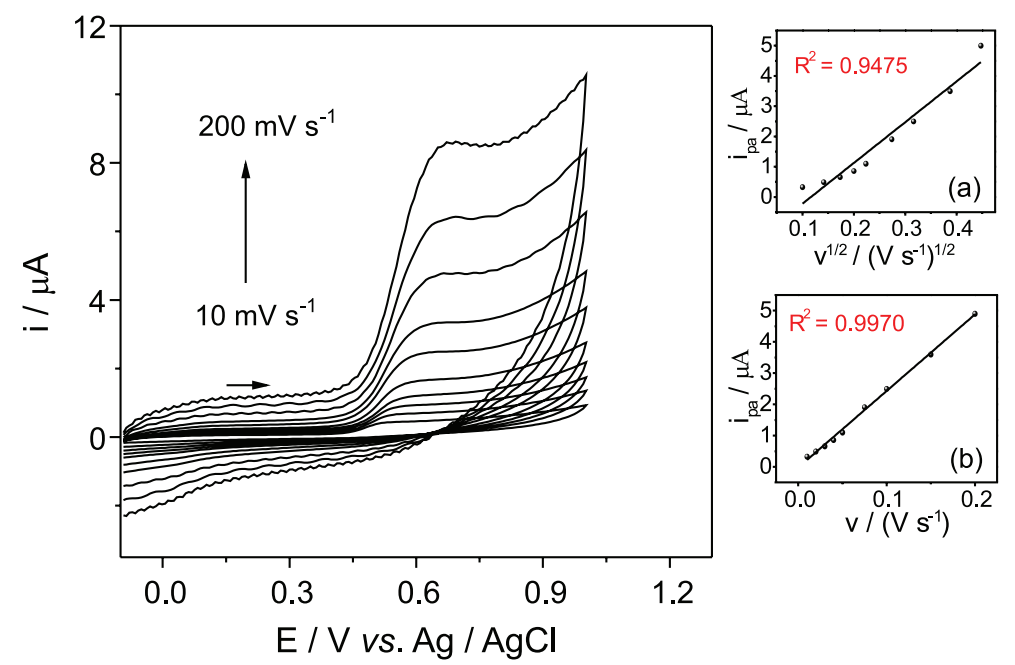

Figure 4. Cyclic voltammograms obtained at different scan rates, using the mag-MIP / GEC, for a solution of $1.0 \times 10^{-4} \mathrm{~mol} \mathrm{~L}^{-1}$ estradiol valerate prepared in $0.1 \mathrm{~mol} \mathrm{~L}^{-1}$ phosphate buffer solution and methanol (50:50, v/v). Insets: (a) $\mathrm{i}_{\mathrm{pa}} v s . \mathrm{v}^{1 / 2}$ and (b) $\mathrm{i}_{\mathrm{pa}} v s . \mathrm{v}$. 
Table 1. Comparison of analytical parameters in the determination of estradiol valerate using electrochemical sensors and mercury electrode

\begin{tabular}{lcccc}
\hline Analyte & Electrode & Linear range / (mol L-1) & LOD / (mol L $\left.{ }^{-1}\right)$ & Reference \\
\hline & FeTPyPz / CPE & $4.5 \times 10^{-5}$ to $4.5 \times 10^{-4}$ & $4.5 \times 10^{-5}$ & 20 \\
Estradiol valerate & $\mathrm{Hg}^{\mathrm{b}}$ & $2.0 \times 10^{-8}$ to $2.0 \times 10^{-6}$ & $1.1 \times 10^{-8}$ & 29 \\
& $\mathrm{Ce}_{2}\left(\mathrm{CO}_{3}\right)_{3} / \mathrm{CPE}^{\mathrm{c}}$ & $2.0 \times 10^{-8}$ to $1.4 \times 10^{-6}$ & $5.6 \times 10^{-9}$ & 30 \\
& mag-MIP / GEC & $5.0 \times 10^{-7}$ to $7.5 \times 10^{-4}$ & $1.0 \times 10^{-8}$ & this work \\
\hline
\end{tabular}

${ }^{\mathrm{a}}$ Carbon paste electrode modified with iron tetrapyridinoporphyrazine; ${ }^{\mathrm{b}}$ mercury electrode; ${ }^{\mathrm{c}}$ carbon paste electrode modified with $\mathrm{Ce}_{2}\left(\mathrm{CO}_{3}\right)$ nanoparticles. LOD: limit of detection; mag-MIP / GEC: graphite-epoxy composite modified with magnetic nanoparticles coated with molecularly imprinted polymer.

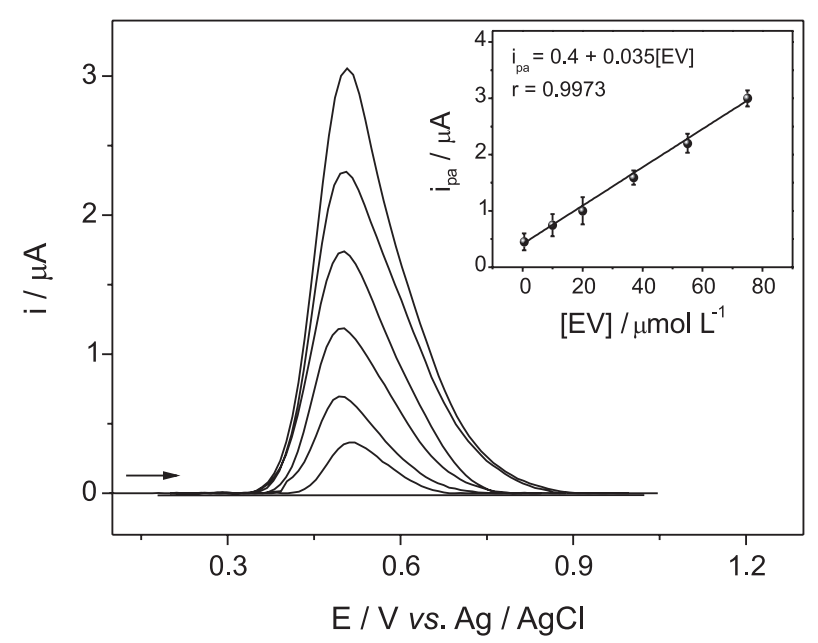

Figure 5. Electrochemical determination of estradiol valerate by SWV using the mag-MIP / GEC sensor in $0.1 \mathrm{~mol} \mathrm{~L}^{-1}$ phosphate buffer solution ( $\mathrm{pH} 7.0)$ and methanol (50:50, v/v). Inset: analytical curve. SWV conditions: $\mathrm{f}=10 \mathrm{~Hz}, \mathrm{a}=75 \mathrm{mV}, \Delta \mathrm{E}_{\mathrm{s}}=5 \mathrm{mV}$.

than $6 \%$, demonstrating that the proposed analytical method exhibited excellent precision and stability in the electrochemical measurements.

In order to obtain information about potential interfering compounds present in different matrices, the mag-MIP / GEC sensor was tested for the analysis of estradiol valerate in the presence of compounds with different chemical structures: urea, uric acid, ascorbic acid, caffeine, dipyrone, diclofenac, bisphenol, $o$-nitrophenol, captopril, 17ß-estradiol and cholesterol (Figure 6). With exception of $17 \beta$-estradiol that showed electrochemical response at the same potential as estradiol valerate $(\mathrm{E}=$ $0.52 \mathrm{~V}$ ) (Figure S4, SI section), the other compounds did not influence the electrochemical response of estradiol valerate, indicating than the molecular impression occurs in the cyclopentano-perhydrophenanthrene (common to all estrogens and that consists of four non-planar rings fused with a total of 17 carbon atoms). However, due to the mag-MIP sensor not showing response to cholesterol indicated the good selectivity only for estradiol derivatives.

The RSD obtained for the peak current of estradiol valerate in the presence of these compounds was $6.7 \%$ $(n=5)$. These results showed the reliability of the proposed method for the sensitive electrochemical determination of estradiol valerate in the presence of different compounds.

\section{Application using different matrices}

The human urine and river water samples were prepared as described in the "Application of the sensor using pharmaceutical, and river water samples" sub-section and were spiked with two known concentrations of estradiol valerate. A solution of the pharmaceutical formulation was prepared using an appropriate mass of the powdered tablets. The sample solutions containing the analyte were injected into the electrochemical cell and were analyzed with the mag-MIP / GEC sensor. Tables 2 and 3 present the recovery percentages obtained

Table 2. Results obtained from analysis different samples

\begin{tabular}{|c|c|c|c|c|c|}
\hline \multirow[b]{2}{*}{ Matrix } & \multirow[b]{2}{*}{$\begin{array}{l}\text { Added / } \\
\left(\mathrm{mol} \mathrm{L}^{-1}\right)\end{array}$} & \multicolumn{2}{|c|}{ Found $^{\mathrm{a}}$} & \multirow{2}{*}{$\begin{array}{l}\text { Recovery }^{\mathrm{b}} \\
\text { (sensor) } / \%\end{array}$} & \multirow{2}{*}{$\begin{array}{l}\text { Relative } \\
\text { error }^{c} / \%\end{array}$} \\
\hline & & $\begin{array}{c}\text { Proposed method / } \\
\left(\mathrm{mol} \mathrm{L}^{-1}\right)\end{array}$ & $\begin{array}{c}\text { Comparative method / } \\
\left(\mathrm{mol} \mathrm{L}^{-1}\right)\end{array}$ & & \\
\hline \multirow{2}{*}{ River water } & $1.0 \times 10^{-6}$ & $(9.2 \pm 0.2) \times 10^{-7}$ & $(9.6 \pm 0.1) \times 10^{-7}$ & 92 & -4.2 \\
\hline & $5.0 \times 10^{-6}$ & $(4.9 \pm 0.1) \times 10^{-6}$ & $(5.0 \pm 0.1) \times 10^{-6}$ & 98 & -2.0 \\
\hline \multirow{2}{*}{ Synthetic urine } & $1.0 \times 10^{-6}$ & $(1.0 \pm 0.3) \times 10^{-6}$ & $(1.1 \pm 0.1) \times 10^{-6}$ & 100 & -9.1 \\
\hline & $5.0 \times 10^{-6}$ & $(4.6 \pm 0.3) \times 10^{-6}$ & $4.9 \pm 0.1) \times 10^{-6}$ & 92 & -6.1 \\
\hline
\end{tabular}

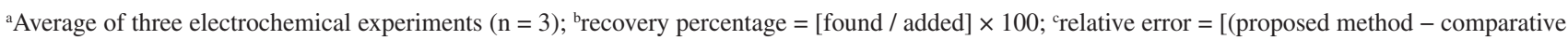
method) / (comparative method) $] \times 100$. 
Table 3. Results obtained from analysis pharmaceutical formulation samples

\begin{tabular}{|c|c|c|c|c|c|}
\hline \multirow[b]{2}{*}{ Matrix } & \multirow[b]{2}{*}{ Nominal value } & Found $^{\mathrm{a}}$ & Found $^{\mathrm{b}}$ & \multirow{2}{*}{$\begin{array}{c}\text { Recovery }^{\mathrm{b}} \\
\text { (sensor) /\% }\end{array}$} & \multirow{2}{*}{$\begin{array}{l}\text { Relative } \\
\text { error }^{\mathrm{c}} / \%\end{array}$} \\
\hline & & $\begin{array}{l}\text { Proposed method / } \\
\left(\mathrm{mol} \mathrm{L}^{-1}\right)\end{array}$ & $\begin{array}{l}\text { Comparative method / } \\
\left(\mathrm{mol} \mathrm{L}^{-1}\right)\end{array}$ & & \\
\hline Drug & $1 \mathrm{mg}$ per tablet & $1.05 \pm 0.05$ & $1.08 \pm 0.01$ & 105 & -2.8 \\
\hline
\end{tabular}

${ }^{a}$ Average of 3 concentrations; ${ }^{b}$ recovery percentage $=[$ found $/$ added $] \times 100$; relative error $=[$ (proposed method - comparative method $) /($ comparative method) $] \times 100$.<smiles>CCc1ccc(O)cc1C</smiles>

nitrophenol<smiles>CC(CS)C(=O)N1CCCC1C(=O)O</smiles>

captopril<smiles>O=c1[nH]c(=O)c2[nH]c(=O)[nH]c2[nH]1</smiles>

uric acid<smiles>Cn1c(=O)c2c(ncn2C)n(C)c1=O</smiles><smiles>O=C1OC(C(O)CO)C(O)=C1O</smiles>

ascorbic acid<smiles>NC(N)=O</smiles>

urea<smiles>Cc1[nH]n(-c2ccccc2)c(=O)c1N(C)CS(=O)(=O)[O-]</smiles>

dipyrone<smiles>O=C(O)Cc1ccccc1Nc1c(Cl)cccc1Cl</smiles>

diclofenac<smiles>CC(C)(c1ccc(O)cc1)c1ccc(O)cc1</smiles>

bisphenol A<smiles>CC(C)CCCC(C)C1CCC2C3CC=C4CC(O)CCC4(C)C3CCC12C</smiles><smiles>Oc1ccc2c(c1)CCC1C2CCC2C(O)CCC21</smiles>

Figure 6. Chemical structures of the compounds used in the interferences study.

for the pharmaceutical, human urine, and river water samples. Recovery percentages close to $100 \%$ for these matrices (ranging from 92 to $100 \%$ ) demonstrated that the proposed electrochemical sensor was able to quantify estradiol valerate without interference effects from concomitant species that might be present in these 
matrices. Comparison of the results obtained using the proposed and comparative methods revealed relative errors ranging from -9.1 to $+1.9 \%$, indicating that the two methods provided similar quantification of estradiol valerate in these matrices, without interference from the concomitants present.

\section{Conclusions}

This work describes the successful development of an electrochemical device based on the mag-MIP / GEC sensor, which could be used for the sensitive and efficient determination of estradiol valerate. The combination of the magnetic properties of the $\mathrm{Fe}_{3} \mathrm{O}_{4}$ and the selectivity of the MIP provides this method with great advantages, compared to other techniques reported in the literature. The magnetic electrode (GEC) developed offers low cost, stability, high repeatability, and capacity of regeneration of electrode surface by simple polishing, and, hence being a reliable alternative method for the detection of estradiol valerate in various media. The magnetic electrode enabled the analysis of different matrices (pharmaceutical, synthetic urine, and river water samples), with recoveries close to $100 \%$. The application of the sensor in the analysis of a pharmaceutical formulation resulted in a concentration close to the nominal value informed by the manufacturer, hence demonstrating that the new method is a highly effective option for the analysis of estradiol valerate.

\section{Supplementary Information}

Supplementary data (HPLC-UV, SWV, etc.) are available free of charge at http://jbcs.sbq.org.br as PDF file.

\section{Acknowledgments}

The authors are grateful for financial support provided by the Brazilian agencies CNPq (grants No. 306650 / 2016-9 and 465571 / 2014-0), CAPES (AUX / PE / PROEX No. 0674 / 2018), and FAPESP (grant No. 2014 / 50945-4). A. W. wishes to acknowledge support provided under the PRODOC-CAPES program.

\section{References}

1. Combalbert, S.; Hernandez-Raquet, G.; Appl. Microbiol. Biotechnol. 2010, 86, 1671.

2. Nash, J. P.; Kime, D. E.; Van der Ven, L. T. M.; Wester, P. W.; Brion, F.; Maack, G.; Stahlschmidt-Allner, P.; Tyler, C. R.; Environ. Health Perspect. 2004, 112, 1725.
3. Cyganek, K.; Klupa, T.; Szopa, M.; Katra, B.; Malecki, M. T.; Pol. Arch. Med. Wewn. 2013, 123, 59.

4. Adeel, M.; Song, X.; Wang, Y.; Francis, D.; Yang, Y.; Environ. Int. 2017, 99, 107.

5. Mazellier, P.; Méité, L.; De Laat, J.; Chemosphere 2008, 73, 1216.

6. Wong, A.; Santos, A. M.; Silva, T. A.; Fatibello-Filho, O.; Talanta 2018, 183, 329.

7. Wackerlig, J.; Schirhagl, R.; Anal. Chem. 2016, 88, 250.

8. Des Azevedo, S.; Lakshmi, D.; Chianella, I.; Whitcombe, M. J.; Karim, K.; Ivanova-Mitseva, P. K.; Subrahmanyam, S.; Piletsky, S. A.; Ind. Eng. Chem. Res. 2013, 52, 13917.

9. Belbruno, J. J.; Chem. Rev. 2018, 119, 94.

10. Zhu, Y.; Kekalo, K.; NDong, C.; Huang, Y.-Y.; Shubitidze, F.; Griswold, K. E.; Baker, I.; Zhang, J. X. J.; Adv. Funct. Mater. 2016, 26, 3953.

11. Zengin, A.; Yildirim, E.; Tamer, U.; Caykara, T.; Analyst 2013, 138, 7238.

12. Tartaj, P.; Morales, M. P.; González-Carreño, T.; VeintemillasVerdaguer, S.; Serna, C. J.; J. Magn. Magn. Mater. 2005, 290291, 28.

13. Uzuriaga-Sánchez, R. J.; Wong, A.; Khan, S.; Pividori, M. I.; Picasso, G.; Sotomayor, M. D. P. T.; Mater. Sci. Eng., C 2017, 74, 365 .

14. Ramimoghadam, D.; Bagheri, S.; Hamid, S. B. A.; J. Magn. Magn. Mater. 2014, 368, 207.

15. Zhao, G.; Wang, H.; Liu, G.; Int. J. Electrochem. Sci. 2017, 12, 8622.

16. Irshad, M.; Iqbal, N.; Mujahid, A.; Afzal, A.; Hussain, T.; Sharif, A.; Ahmad, E.; Athar, M.; Nanomaterials 2013, 3, 615.

17. Selvolini, G.; Marrazza, G.; Sensors 2017, 17, 718.

18. Yáñez-Sedeno, P.; Campuzano, S.; Pingarrón, J. M.; Anal. Chim. Acta 2017, 960, 1.

19. Bojdia, M. K.; Behbahanib, M.; Hesam, G.; Mashhadizadeh, M. H.; RSC Adv. 2016, 6, 32374.

20. Batista, I. V.; Lanza, M. R. V.; Dias, I. L. T.; Tanaka, S. M. C. N.; Tanaka, A. A.; Sotomayor, M. D. P. T.; Analyst 2008, 133, 1692.

21. Pividori, M. I.; Alegret, S.; Anal. Lett. 2003, 36, 1669.

22. Lu, F.; Sun, M.; Fan, L.; Qiu, H.; Li, X.; Luo, C.; Sens. Actuators, B 2012, 173, 591.

23. Fan, L.; Luo, C.; Lv, Z.; Lu, F.; Qiu, H.; J. Hazard. Mater. 2011, 194, 193.

24. Laube, N.; Mohr, B.; Hesse, A.; J. Cryst. Growth 2001, 233, 367.

25. Uzuriaga-Sánchez, R. J.; Khan, S.; Wong, A.; Picasso, G.; Pividori, M. I.; Sotomayor, M. D. P. T.; Food Chem. 2016, 190, 460.

26. Pan, S.; Shen, H.; Zhou, L.; Chen, X.; J. Mater. Chem. A 2014 , 2, 15345 .

27. Jin, G. P.; Lin, X. Q.; Electrochim. Acta 2005, 50, 3556. 
28. Moraes, F. C.; Rossi, B.; Donatoni, M. C.; de Oliveira, K. T.; Pereira, E. C.; Anal. Chim. Acta 2015, 881, 37.

29. Duan, J. P.; Chen, G. N.; Chen, M. L.; Wu, X. P.; Chen, H. Q.; Analyst 1999, 124, 1651.
30. Morshedi, M.; Mofidi, Z.; Norouzi, P.; Shahabi, S.; Int. J. Electrochem. Sci. 2018, 13, 11238.

Submitted: February 14, 2019

Published online: June 21, 2019 